\title{
Pancratistatin induces apoptosis and autophagy in metastatic prostate cancer cells
}

\author{
CARLY GRIFFIN $^{1}$, JAMES McNULTY ${ }^{2}$ and SIYARAM PANDEY ${ }^{1}$ \\ ${ }^{1}$ Department of Chemistry and Biochemistry, University of Windsor, 401 Sunset Avenue, Windsor, Ontario N9B 3P4; \\ ${ }^{2}$ Department of Chemistry, McMaster University, 1280 Main Street West, Hamilton, Ontario L8S 4M1, Canada
}

Received December 13, 2010; Accepted January 14, 2011

DOI: 10.3892/ijo.2011.977

\begin{abstract}
The Amaryllidaceae alkaloid pancratistatin has been proven to selectively induce apoptotic cell death in a variety of human cancer cells with an insignificant effect on noncancerous cells. In this study we report, for the first time, the effects of pancratistatin (PST) on models of metastatic prostate cancer. The effects of pancratistatin on prostate cancer DU145 and LNCaP cell lines was assessed by microscopy, enzymatic activity assays and Western blotting. Apoptosis was determined by nuclear condensation and caspase activation, and autophagy was observed by MDC staining and LC3 expression levels. Human prostate xenografts were used to test the potential therapeutic efficacy of intra-tumor administration of pancratistatin in vivo. Pancratistatin treatment reduced cell viability and induced apoptosis in androgen-responsive ( $\mathrm{LNCaP}$ ) and androgen-refractory (DU145) prostate cancer cell lines in a dose- and time-dependent manner, but with an insignificant effect on normal human fibroblast (NHF) cells at the effective dose. Increased reactive oxygen species production and collapse of mitochondrial membrane potential resulted from treatment with pancratistatin in both cancer cell lines. This study presents the novel finding that pancratistatin treatment caused decreased migration capacity and increased autophagy levels in metastatic prostate cancer cells. Importantly, in this proof-of-concept study, pancratistatin reduced the volume of xenograft tumors compared to control-treated animals, and was well-tolerated. Our results highlight the potential of pancratistatin for clinical development as a selective therapeutic for treatment of metastatic prostate cancer.
\end{abstract}

\section{Introduction}

Natural alkaloids of the Amaryllidaceae family of plants have been used in traditional medicine for centuries and have wide-ranging properties such as anti-viral, anti-bacterial and

Correspondence to: Dr Siyaram Pandey, Department of Chemistry and Biochemistry, University of Windsor, 401 Sunset Avenue, Windsor, Ontario N9B 3P4, Canada

E-mail: spandey@uwindsor.ca

Key words: mitochondria, androgen independent, reactive oxygen species, DU145 xenograft anti-neoplastic activity (1). The phenanthridone alkaloid pancratistatin (PST), isolated from the bulb tissues of Hymenocallis littoralis plants, has shown potential to be a potent anti-cancer agent with a notable therapeutic window, albeit with an elusive target (2). Our previous studies indicated that pancratistatin selectively and effectively induces apoptosis associated with mitochondrial destabilization and increased reactive oxygen species (ROS) production in human leukemia, melanoma and hormone-refractory breast carcinoma cells (3-5). We recently reported that pancratistatin-induced apoptosis occurs in a p53-independent manner and that cancer cell mitochondria are essential for the anti-cancer activity of pancratistatin (2).

The intrinsic pathway of apoptosis involves loss of mitochondrial membrane potential, permeabilization of the outer mitochondrial membrane, and release of pro-apoptotic proteins to the cytosol (6). Mitochondria-mediated apoptosis may be induced by increased reactive oxygen species (ROS) production, which is an indicator of cellular stress (7). Mitochondria, and more specifically mitochondrial respiratory chain (MRC) complexes I and III, are the primary sources of cellular ROS production (7). A review of recent literature reveals the potent anti-cancer properties of natural compounds that specifically target mitochondria or metabolic pathways, including Resveratrol, betulinic acid and the vitamin E analog $\alpha$-tocopheryl succinate ( $\alpha$-TOS) (8-10). $\alpha$-TOS induces apoptosis in cancer cells via ROS generation by blocking MRC complex II activity (11). Additionally, Xiao and colleagues reported that isothiocyanates (constituents of cruciferous vegetables) generate excessive ROS by inhibiting oxidative phosphorylation, leading to mitochondrial-mediated apoptosis in prostate cancer cells (12).

There are limited therapy options for hormone-refractory metastatic prostate carcinoma and patients often have poor prognosis. Recent studies have reported that a novel therapeutic strategy for advanced androgen-independent prostate cancer may be to target autophagy (13). Autophagy is a lysosomal process of self-digestion, which is understood to be a survival mechanism employed by cells facing adverse environmental conditions, such as nutrient deprivation or hypoxia (14). Tumor cells use the self-preservation facet of autophagy to overcome chemotherapeutic insult, thereby acquiring resistant phenotypes (15). Thus a novel strategy for treatment is to combine standard chemotherapy with inhibition of autophagy, which may re- 
sensitize resistant tumor cells $(16,17)$. Conversely, several reports indicate that sustained autophagy actually results in programmed cell death type-II, or autophagic cell death, in cancer cells and that induction of autophagy may be a valid treatment tactic $(18,19)$.

The interplay between apoptosis and autophagy involves regulation of autophagy by classically defined anti-apoptotic proteins, such as Bcl-2 and Bcl-XL (15). Another key regulator of apoptosis and autophagy processes is the tumor suppressor p53 (20). Of note, the two metastatic prostate cancer cell lines studied not only differ in their androgen sensitivity, but also in p53 status. DU145 cells are both androgen-refractory and contain functionally mutated p53 protein, and LNCaP cells maintain androgen sensitivity and wild-type p53 (21). In this study, both cell lines were observed to undergo apoptosis induced by pancratistatin, which caused increased ROS production, and destabilization of the mitochondrial membrane potential. For the first time, we report the effect of pancratistatin on induction of autophagy, as well as the efficacy of pancratistatin against xenograft models of DU145 prostate tumors.

\section{Materials and methods}

Chemicals. Media, gentamycin, L-glutamine, amino acids, Hoechst 33342 dye, Tetramethyl Rhodamine Methyl Ester (TMRM) dye, and Annexin-V AlexaFluor 488 are products of Invitrogen (Gibco). Caspase-3 and -9 fluorometric substrates were purchased from Calbiochem. Cell proliferation reagent WST-1 was purchased from Roche. Anti-LC3 antibody was purchased from Abcam, and anti- $\beta$-actin antibody was purchased from SantaCruz Biotechnology. Pancratistatin (Fig. 1A) was isolated from $H$. littoralis as previously described (22) and provided by Dr J. McNulty. All other chemicals were purchased from Sigma-Aldrich.

Cell culture. Androgen-sensitive human prostate $\mathrm{LNCaP}$ cells, which express wild-type p53, and androgen-refractory, p53 mutant DU145 cells were purchased from ATCC (23). LNCaP cells were grown in RPMI media and DU145 cells were grown in DMEM; supplemented as recommended by ATCC. Human diploid fibroblast (AG09309) cells (NHF), purchased from the Coriell Institute for Medical Research, were grown in Earle's minimum essential medium supplemented with $15 \%$ (v/v) fetal bovine serum, $2 \mathrm{mM} \mathrm{L}$-glutamine, $1.5 \mathrm{~g} / \mathrm{l}$ sodium bicarbonate, essential and non-essential amino acids, vitamins, and gentamycin. All cultures were maintained at 5\% $\mathrm{CO}_{2}$ and $37^{\circ} \mathrm{C}$.

Cytotoxicity assays. Cytotoxicity was measured using the WST-1 colorimetric assay. Cells were seeded at 2000 cells/ well in 96-well tissue culture plates. After treatment with pancratistatin as indicated, cells were incubated with WST-1 according to manufacturer's protocol for $4 \mathrm{~h}$ at $37^{\circ} \mathrm{C}$. Absorbance was measured at $450 \mathrm{~nm}$ on a Victor ${ }^{3}$ microplate reader. Absorbance is directly proportional to the number of living cells in culture. Each assay was performed in triplicate and the mean of three assays was calculated based on average absorbance of control-treated $\left(\mathrm{Me}_{2} \mathrm{SO}\right)$ cells.
Assessment of apoptosis. Cells were treated as indicated and nuclear morphology was evaluated by fluorescence microscopy using cell-permeable Hoechst 33342 dye. The percent of condensed nuclei (indicative of apoptosis) was calculated as: [(number of cells with condensed, brightly stained nuclei/ total number of cells)*100] with a minimum 5 fields counted with 100 cells/field. To monitor phosphatidyl serine exposure, Annexin-V binding assay was performed. Cells were treated as indicated, trypsinized and washed twice in room temperature PBS, then re-suspended in Annexin-V binding buffer $(10 \mathrm{mM}$ HEPES/ $\mathrm{NaOH} \mathrm{pH} \mathrm{7.5,} 140 \mathrm{mM} \mathrm{NaCl}, 2.5 \mathrm{mM} \mathrm{CaCl}_{2}$ ), containing Annexin-V AlexaFluor 488 conjugate (1:50) for $15 \mathrm{~min}$ at $25^{\circ} \mathrm{C}$; images were captured on an inverted fluorescence microscope (Leica DM IRB, Germany).

Trypan blue exclusion viability assay. Cell viability was assessed by trypan blue exclusion after incubation of cells at increasing intervals with $1 \mu \mathrm{M}$ pancratistatin. Cells were trypsinized and the cell pellet was resuspended in PBS. Cell suspension was diluted (1:1) with trypan blue exclusion dye and cells were counted using a Fisher Hemocytometer. Data represent the mean of three assays calculated as percent trypan blue positive per total cells counted.

Mitochondrial functionality assays. Mitochondrial membrane potential (MMP) was observed using cell permeable TMRM dye (1 $\mu \mathrm{M}$ final concentration). Cells were grown on coverslips and following treatment TMRM was added directly to the media and incubated for $30 \mathrm{~min}$ at $37^{\circ} \mathrm{C}$ in darkness; cell permeable Hoechst dye was added for the last $5 \mathrm{~min}$ of the incubation period, to observe nuclear morphology. To detect generation of reactive oxygen species (ROS) cells were treated with pancratistatin, trypsinized and counted using the trypan blue exclusion assay prior to incubation with $\mathrm{H}_{2}$ DCFDA $(1 \mu \mathrm{M})$ for $45 \mathrm{~min}$ at $37^{\circ} \mathrm{C}$ in an opaque 96 -well plate. Fluorescence was measured at $513 \mathrm{~nm}$ excitation and $530 \mathrm{~nm}$ emission using a SpectraMax GeminiXPS spectrofluorometer. Change in ROS generation was calculated as the fold difference from control (RFU) and expressed per 10,000 cells.

Assessment of caspase activity. Caspase activity assays were carried out using a previously published method (3). Briefly, cellular lysate was collected from LNCaP and DU145 cells and incubated with the desired fluorogenic substrate (caspase-3, DEVD-AFC; caspase-8, IETD-AFC; caspase-9, LEHD-AFC) in assay buffer (0.1 M HEPES, pH 7.4, 2 mM DTT, 0.1\% CHAPS, $1 \%$ sucrose) and allowed to incubate at $37^{\circ} \mathrm{C}$ for $45 \mathrm{~min}$. Fluorescence was measured at $400 \mathrm{~nm}$ excitation and $505 \mathrm{~nm}$ emission using a SpectraMax Gemini XPS spectrofluorometer. Caspase activity was calculated per microgram of protein, and expressed as a percentage of control activity.

Wound-healing assay. Prostate cancer cells were seeded in 12 -well plates and cultured to at least $95 \%$ confluence. Monolayer cells were scraped with a plastic $200 \mu$ l pipette tip, rinsed with warmed PBS and immediately cultured in fresh media with or without $1 \mu \mathrm{M}$ pancratistatin. Phase-contrast microscopy was used to observe the wound-area at 0,24 and $48 \mathrm{~h}$ after treatment. The relative migration distance $(\%)$ is equal to 
A<smiles>O=C1N[C@@H]2c3c(cc4c(c3O)OCO4)[C@@H]2[C@@H](O)[C@@H](O)[C@@H]1O</smiles>

C
DU145

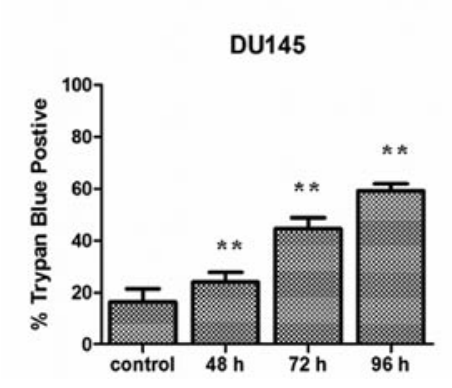

B

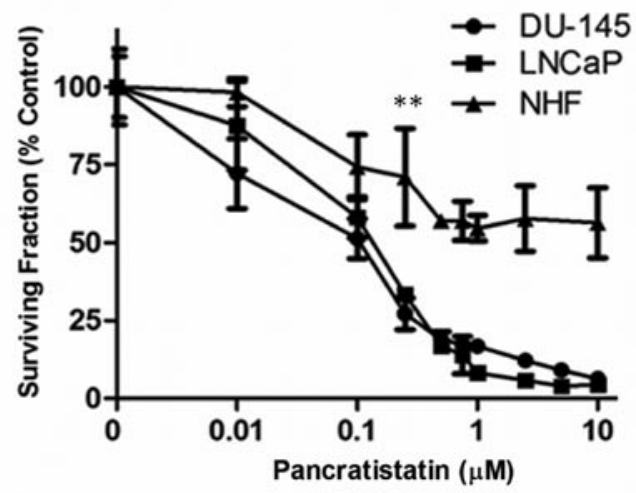

LNCaP

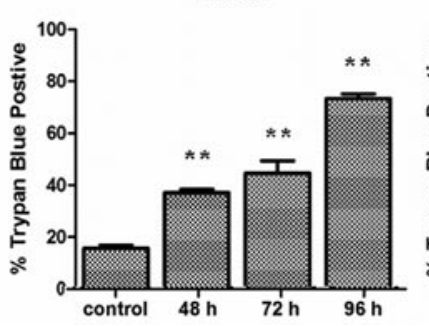

NHF

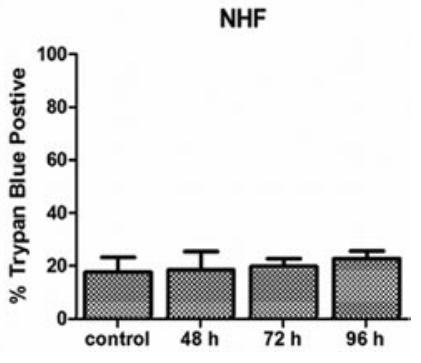

Figure 1. Pancratistatin selectively affects viability of prostate carcinoma cells. (A) Chemical structure of pancratistatin. (B) DU145, LNCaP and NHF cells were treated with control $\left(\mathrm{Me}_{2} \mathrm{SO}\right)$ or the indicated doses of pancratistatin for $72 \mathrm{~h}$. Cytotoxicity was measured by the WST-1 colorimetric assay. Data points, mean $(n=3)$; bars, $S D ;{ }^{* * *} \mathrm{P}<0.005$, significantly different between cell lines by paired t-test. (C) DU145, LNCaP and NHF cells treated for the indicated times with control $\left(\mathrm{Me}_{2} \mathrm{SO}\right)$ or $1 \mu \mathrm{M}$ pancratistatin (PST). Cell viability was determined by trypan blue dye exclusion assay. Columns, mean (n=3); bars, SD; ${ }^{* *} \mathrm{P}<0.005$, significantly different from control by one-way ANOVA.

(A-B)/A*100, where $\mathrm{A}$ is the wound width before, and $\mathrm{B}$ is the wound width after incubation.

Monitoring autophagic vacuole formation. To detect the formation of autophagic vacuoles, cells were grown on coverslips and treated as indicated. Monodansylcadaverine $(0.1 \mathrm{mM}$ final concentration) was added directly to the media and incubated at $37^{\circ} \mathrm{C}$ for $20 \mathrm{~min}$ in darkness; images were captured on an inverted fluorescence microscope (Leica DM IRB, Germany).

Western blot analysis. Cells treated with pancratistatin were mechanically lysed in ice-cold hypotonic buffer with protease inhibitors (10 mM Tris $\mathrm{HCl} \mathrm{pH} 7.2,5 \mathrm{mM} \mathrm{KCl}, 1 \mathrm{mM} \mathrm{MgCl}{ }_{2}$, $1 \mathrm{mM}$ EGTA, 1\% Triton X-100; $10 \mu \mathrm{M}$ Leu-pep and Pep-A, $100 \mu \mathrm{M}$ PMSF $)$. Protein samples $(20 \mu \mathrm{g})$ were separated by SDS-PAGE, transferred to nitrocellulose and probed with the indicated primary antibody (1:1000) overnight at $4^{\circ} \mathrm{C}$. Membranes were then incubated with HRP-conjugated secondary antibody (1:1000) for $1 \mathrm{~h}$ at $25^{\circ} \mathrm{C}$ and visualized using enhanced chemiluminescence reagent. Equal loading of the protein samples was confirmed by parallel Western blots for $\beta$-actin. Images were digitized and band intensity was quantified using NIH Image $\mathbf{J}$ software.

In vivo xenograft models. Six-week old male homozygous CD-1 nude mice (25-30 g) were obtained from Charles River Laboratories, St. Constant, QC. Animals were housed in constant laboratory conditions of a $12 \mathrm{~h}$ light/dark cycle at $21^{\circ} \mathrm{C}$ in accordance with institutional animal protocols (University of Windsor Research Ethics Board-AUPP05). Prior to injection, DU145 cells were washed with PBS and centrifuged at $500 \mathrm{x} \mathrm{g}$ for $5 \mathrm{~min}$; cell pellets were suspended

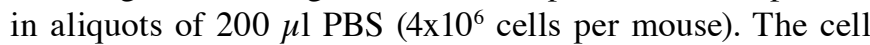
suspension was injected s.c. in the right hind flank. Tumors were allowed to grow for 4 weeks and thereafter animals were randomized into two treatment groups $(n=3)$. Animals were treated intra-tumorally (i.t.) with vehicle (5 $\mu 1 \mathrm{Me}_{2} \mathrm{SO}$ in PBS) or pancratistatin $(3 \mathrm{mg} / \mathrm{kg}) 4$ times over 3 weeks $(24,25)$. Tumors were assessed at the end of the study by 2D digital volume extrapolation; measurements of the tumor length and width were normalized to $1 \mathrm{~cm}$ on the ruler pictured in each image, using Image $\mathbf{J}$ software. Body weight of all animals was taken twice weekly during the study as a measure of overt toxicity. Intraperitoneal injection of $3 \mathrm{mg} / \mathrm{kg}$ pancratistatin twice weekly for up to 2 months was previously shown to be non-toxic to liver and kidneys by histopathological analysis (2).

Statistical analysis. Data are presented as the mean \pm SD and significance was determined by using Student's t-test or ANOVA, where appropriate. ${ }^{*} \mathrm{P}<0.05$ and ${ }^{* *} \mathrm{P}<0.005$ were considered significant.

\section{Results}

Cytotoxic effect of pancratistatin on prostate cancer cells. To determine whether pancratistatin selectively effects prostate cancer cell viability, we tested this natural alkaloid on androgen- 
A
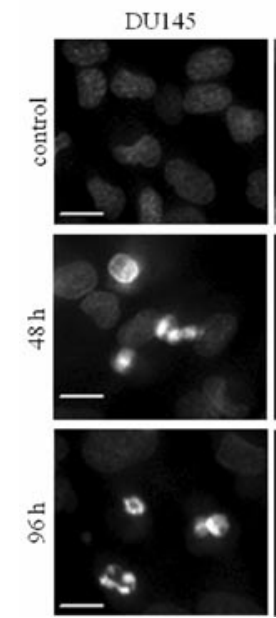

LNCaP
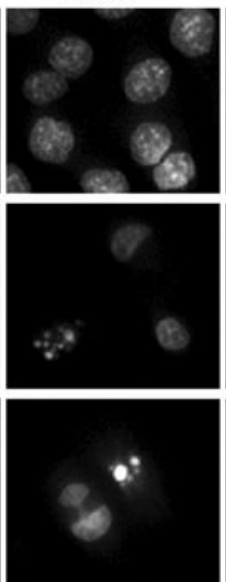

B
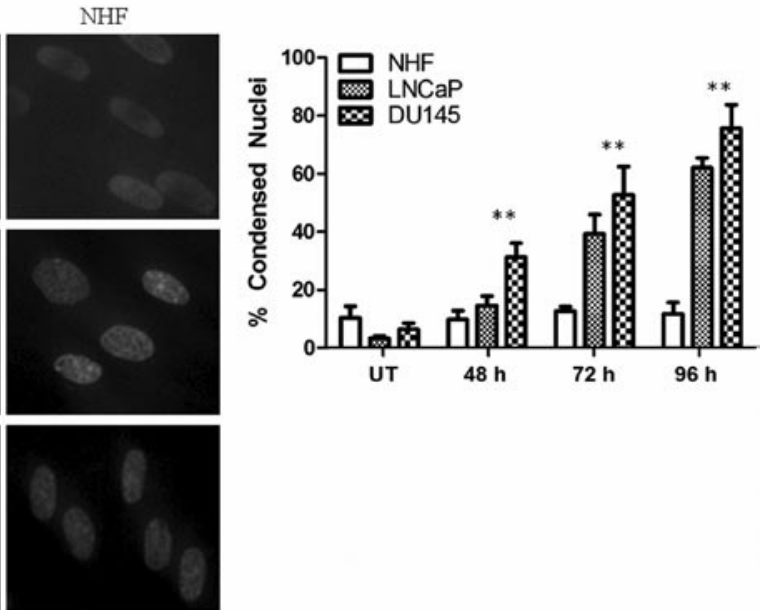

Figure 2. Pancratistatin induces apoptosis in prostate cancer cells. (A) Representative nuclear morphology of Du145, LNCaP and NHF cells stained with Hoechst dye after $72 \mathrm{~h}$ with $1 \mu \mathrm{M}$ pancratistatin (PST) or control $\left(\mathrm{Me}_{2} \mathrm{SO}\right.$ ). Scale bars represent $15 \mu \mathrm{m}$. (B) Quantification of condensed brightly stained nuclei by Hoechst dye, characteristic of apoptotic cells. DU145 (AR-) and LNCaP (AR+) cells were treated with control (Me 2 SO) or $1 \mu \mathrm{M}$ pancratistatin for 48 , 72 or $96 \mathrm{~h}$ and stained with Hoechst. A minimum 5 fields with 100 cells/field was counted. Columns, mean $(\mathrm{n}=6)$; bars, $\mathrm{SD}$; ${ }^{* *} \mathrm{P}<0.005$, significantly different from control by two-way ANOVA.

responsive LNCaP cells and androgen-refractory DU145 cells, as well as non-cancerous human fibroblast NHF cells. Cytotoxicity was assessed following exposure to increasing concentrations of pancratistatin over $72 \mathrm{~h}$ (Fig. 1B). An $\mathrm{EC}_{50}$ value of approximately $100 \mathrm{nM}$ resulted for both cancer cell lines. Treatment of NHF cells with pancratistatin for $72 \mathrm{~h}$ did not cause viability to drop below 50\% (Fig. 1B). To further test this result the trypan blue exclusion assay was used, which confirmed that at $1 \mu \mathrm{M}$, pancratistatin selectively decreases viability of LNCaP and DU145 prostate cancer cells, but does not significantly increase cell death in non-cancerous NHF cells (Fig. 1C). These results suggest that pancratistatin selectively reduces viability of cancer cells regardless of androgen sensitivity with an insignificant effect on non-cancerous cells.

Pancratistatin induces apoptosis in metastatic prostate cells. Pancratistatin has been shown to effectively induce apoptosis in breast cancer cells, independent of estrogen receptor status in vitro, and in acute and chronic forms of leukemia ex vivo $(5,26)$. To investigate whether the observed cytotoxicity of $1 \mu \mathrm{M}$ pancratistatin on prostate cancer cells was due to induction of apoptosis, we performed Hoechst staining at 48 and $96 \mathrm{~h}$ of treatment. In both DU145 and LNCaP cell lines; there were an increased number of cells with brightly stained, condensed nuclei (Fig. 2A). Moreover, in both prostate cancer cell lines, there was a marked increase in Annexin-V positive cells, indicative of phosphatidyl serine exposure, a characteristic marker of apoptosis (not shown). In line with previous reports $(2,5)$, pancratistatin did not affect nuclear morphology in non-cancerous cells (Fig. 2A). Exposure to pancratistatin for increased lengths of time resulted in increased apoptotic morphology in cancer cells, with a $70 \%$ increase in apoptosis over control after $96 \mathrm{~h}$ in both prostate cancer cell lines. There was an insignificant change in the number of cells with apoptotic nuclear morphology in NHFs exposed to pancratistatin at all
A
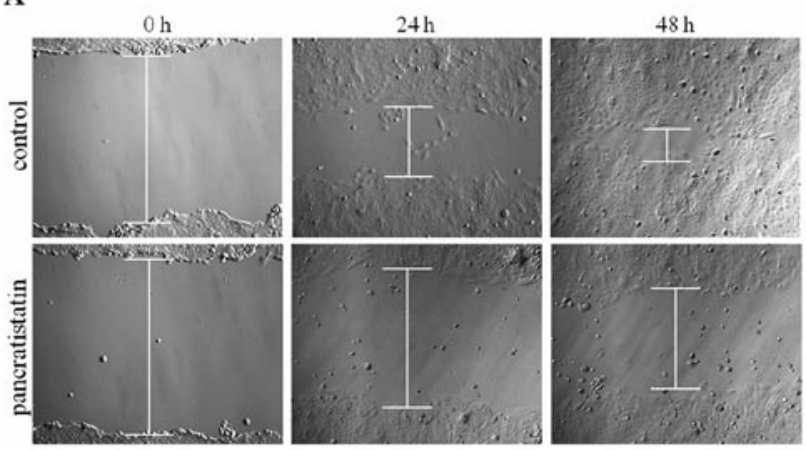

B

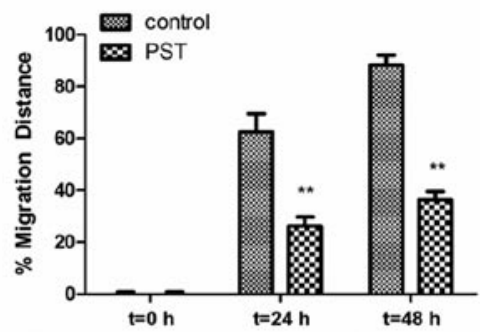

Figure 3. Pancratistatin reduces wound-healing capacity. (A) Wound healing capacity, indicative of migration potential, was decreased in DU145 cells after treatment with pancratistatin compared to control. Images represent data obtained from three independent experiments. (B) Quantification of wound healing capacity. Percent migration distance was calculated in relation to the mean width of the wound at $0 \mathrm{~h}$, as: $\left.\left[100^{*}(\mathrm{~A}-\mathrm{B}) / \mathrm{A}\right)\right]$; where $\mathrm{A}$ is the mean wound width at $\mathrm{t}=0 \mathrm{~h}$, and $\mathrm{B}$ is the mean wound width at the indicated treatment time. Columns, mean $(\mathrm{n}=5)$; bars, $\mathrm{SD} ;{ }^{* *} \mathrm{P}<0.005$, significantly different from control by two-way ANOVA.

time points (Fig. 2B). These findings indicate that pancratistatin induces apoptosis selectively in prostate carcinoma cells.

Inhibition of migration of prostate cancer cells by pancratistatin using the wound healing assay. Metastatic prostate cancer is 
A

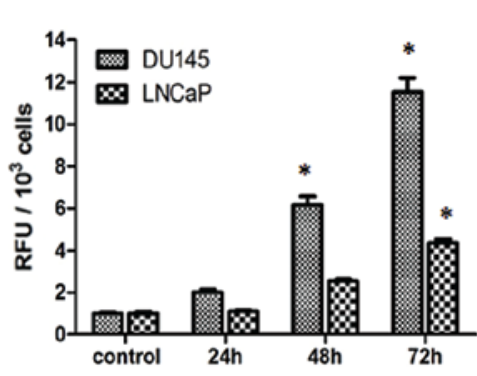

B
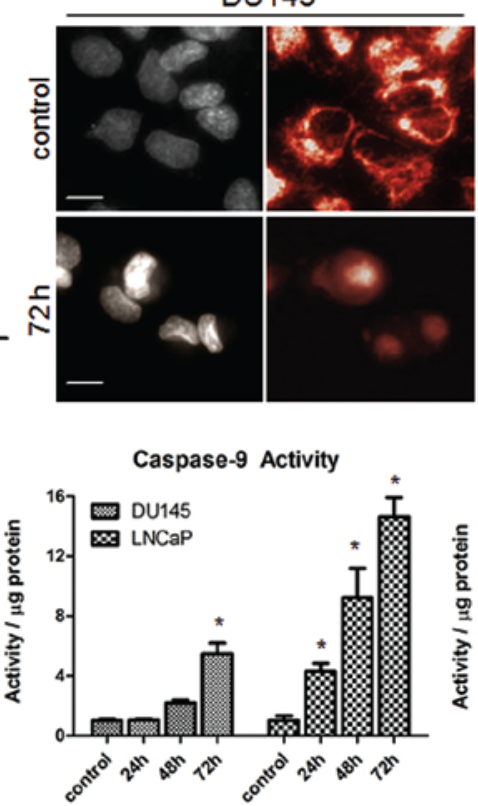
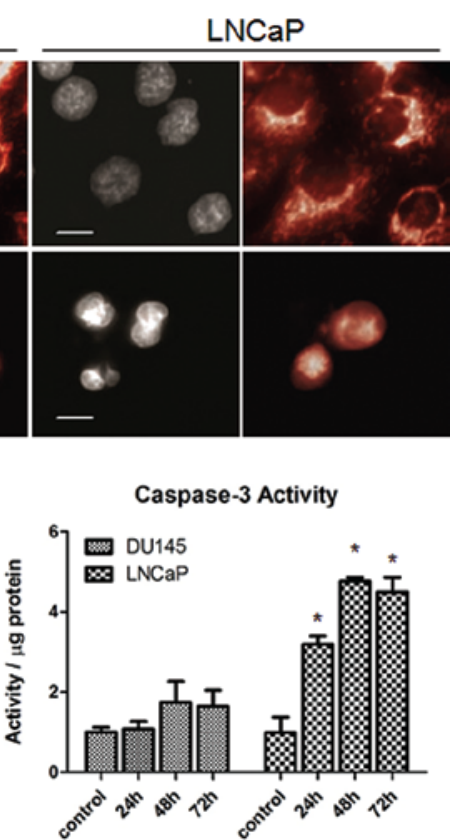

Figure 4. Pancratistatin selectively affects mitochondrial function of prostate cancer cells. (A) Measurement of whole-cell ROS production in DU145 and $\mathrm{LNCaP}$ cells after indicated length of exposure to control $\left(\mathrm{Me}_{2} \mathrm{SO}\right)$ or $1 \mu \mathrm{M}$ pancratistatin. Fluorescence generated by the oxidized product of $\mathrm{H}_{2} \mathrm{DCFDA}$ is expressed as fold-difference of control per 10,000 cells in relative fluorescence units (RFU) and is indicative of cellular ROS levels. Columns, mean ( $=3$ ); bars, SD; ${ }^{\mathrm{P}}<0.05$, significantly different from control by paired t-test. (B) Representative fluorescence micrographs of DU145, LNCaP and NHF cells stained with Hoechst and TMRM dye after $72 \mathrm{~h}$ with $1 \mu \mathrm{M}$ pancratistatin (PST) or control $\left(\mathrm{Me}_{2} \mathrm{SO}\right)$. Scale bars represent $15 \mu \mathrm{m}$. Pancratistatin induced MMP collapse in DU145 and LNCaP cells. (C) Caspase-3, -8 and -9 activity was assayed in DU145 and LNCaP cells following treatment with control (Me 2 SO) or $1 \mu$ M pancratistatin for the indicated time points. Cleavage of caspase-specific fluorogenic substrates indicates the level of caspase activity in the sample. Caspase activity was calculated relative to control and expressed as activity (RFU) per microgram protein. Columns, mean ( $\mathrm{n}=3$ ); bars, $\mathrm{SD}$; ${ }^{*} \mathrm{P}<0.05$, significantly different from control by paired t-test.

associated with poor prognosis, and agents that inhibit migration of tumor cells may prevent metastatic disease progression. To evaluate the anti-migratory effect of pancratistatin on metastatic prostate cancer cells, we monitored the wound healing capacity of DU145 prostate cancer cells. A scratch-wound was made in a sub-confluent cell monolayer and cells were allowed to migrate into the cell-free area for up to $48 \mathrm{~h}$ (Fig. 3A). Pancratistatin treatment caused a $35 \%$ reduction in the ability of prostate cancer cells to migrate into the wound-area compared to control at $24 \mathrm{~h}$, and a $50 \%$ reduction after $48 \mathrm{~h}$ (Fig. 3B). This result clearly shows that pancratistatin affects the migration capacity of metastatic prostate cancer cells in vitro.

Pancratistatin induces ROS production. Due to its selective anti-cancer activity we hypothesized that pancratistatin may be targeting the mitochondria of cancer cells, which have distinct properties and metabolic alterations from normal mitochondria (8). Increasing reports indicate that mitochondrialmediated ROS production activates apoptotic cell death in cancer cells more potently than in non-cancerous cells $(6,27)$. Here we report that pancratistatin treatment increased ROS production in metastatic prostate cancer cells and that longer treatment with pancratistatin corresponded with higher ROS levels, up to $72 \mathrm{~h}$. As shown in Fig. 3A, ROS production in p53-mutant DU145 cells was significantly higher than control, with as much as 10-fold increase in ROS production after $72 \mathrm{~h}$ exposure to pancratistatin. Treatment with pancratistatin also increased ROS production in wild-type p53 LNCaP cells, albeit to a lesser extent than in DU145 cells, causing an approximate 5-fold increase over control after $72 \mathrm{~h}$ (Fig. 4A). This result suggests pancratistatin induced ROS production in prostate cancer cells, which may be modulated by p53 function.

Loss of mitochondrial membrane potential results from exposure to pancratistatin. Pancratistatin has previously been shown to cause selective dissipation of mitochondrial membrane potential in melanoma and colorectal adenocarcinoma cells $(2,4)$. To determine whether pancratistatin elicits a similar response in metastatic prostate cancer cells, mitochondrial membrane potential was monitored using TMRM dye following $72 \mathrm{~h}$ exposure to pancratistatin. Pancratistatin treatment resulted in near complete loss of TMRM puncta, which indicates collapse of the mitochondrial membrane potential, in both DU145 and LNCaP cells (Fig. 4B). When paired with the observed increase in ROS production, this result suggests that pancratistatin induces mitochondrial-mediated apoptotic cell death.

Caspase activation following pancratistatin treatment. Regardless of whether the extrinsic or intrinsic pathway of apoptosis is induced, apoptotic cell death typically culminates with cleavage and activation of caspases. Mechanistically, caspase-9 is activated upstream of caspase-3, and downstream of mitochondrial membrane permeabilization, thus indicates that the intrinsic pathway of apoptosis is being induced. Caspase- 8 becomes activated following death-receptor stimulation, which is characteristic of extrinsically-mediated apoptotic cell death. To delineate the apoptosis pathway activated by pancratistatin, time-based caspase-activity profiling was performed. 
A

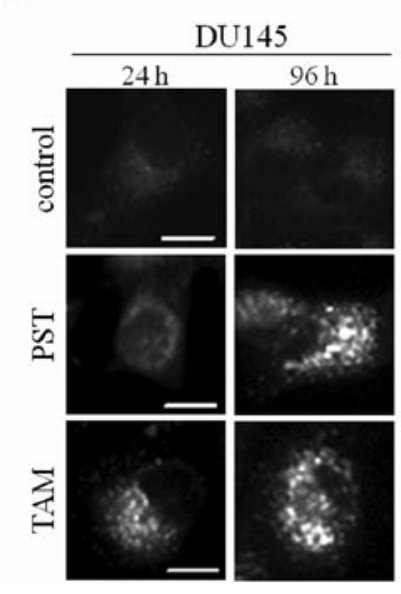

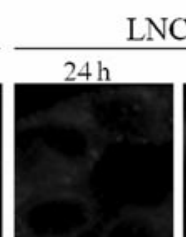

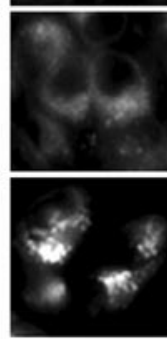

B

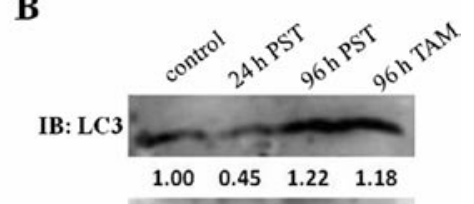

Figure 5. Pancratistatin induces autophagy in androgen-refractory prostate cancer cells. (A) Representative images of DU145 and LNCaP cells stained with MDC after 24 and $96 \mathrm{~h}$ with control $\left(\mathrm{Me}_{2} \mathrm{SO}\right), 1 \mu \mathrm{M}$ pancratistatin (PST) or $5 \mu \mathrm{M}$ Tamoxifen (TAM). Scale bars represent $15 \mu \mathrm{m}$. (B) DU145 cells were treated with control ( $\mathrm{Me}_{2} \mathrm{SO}$ ), $1 \mu \mathrm{M}$ pancratistatin (PST) for 24 and $96 \mathrm{~h}$, or $5 \mu \mathrm{M}$ Tamoxifen (TAM) for $96 \mathrm{~h}$. Post-nuclear lysate was separated by SDSPAGE followed by immunoblotting using specific antibodies against LC-3 or $\beta$-actin. Immunoblot images were digitized and optical densities were quantified using NIH Image J software.

Pancratistatin treatment resulted in caspase-9 activation in prostate cancer cells; with 4-fold increase over control in LNCaP cells after only $24 \mathrm{~h}$ and approximately 5-fold increase in DU145 cells after 72 h (Fig. 4C). Caspase-9 activation correlated with increased caspase-3 activation in LNCaP cells, resulting in 5-fold increased activity over control after $48 \mathrm{~h}$ treatment. Interestingly, activation of caspase-3 in androgenrefractory, p53-mutant DU145 cells was much less pronounced (less than 2-fold increase) after $72 \mathrm{~h}$ pancratistatin treatment. Caspase- 8 activity did not significantly increase in either cell line in response to pancratistatin exposure (Fig. 4C). Taken together these findings indicate that pancratistatin leads to activation of caspases involved in the intrinsic pathway of apoptosis.

Induction of autophagic cell death by pancratistatin in p53mutant prostate cancer cells. Autophagy is a process of selfdigestion induced in response to nutrient deprivation, and may be used by tumor cells to survive adverse conditions in the tumor microenvironment. Sustained autophagy however, can be detrimental to a cell, resulting in autophagic cell death. To determine whether pancratistatin affects levels of autophagy in metastatic prostate cancer cells, DU145 and LNCaP cells were treated with $1 \mu \mathrm{M}$ pancratistatin or $5 \mu \mathrm{M}$ Tamoxifen, an estrogen-receptor antagonist known to induce autophagy in cancer cells. Compared to control-treated cells, there was an increase in autophagic vacuoles visualized by MDC staining in DU145 cells after $96 \mathrm{~h}$ with pancratistatin, but no observable change in LNCaP cells (Fig. 5A) As anticipated, Tamoxifen induced non-lethal autophagy in both cell lines, at both 24 and $96 \mathrm{~h}$ (Fig. 5A). To further confirm pancratistatin-induced autophagy in DU145 cells, we analyzed the expression level of microtubule-associated protein1 light chain 3 (LC3), an important marker and effector of autophagy. Indeed, after $96 \mathrm{~h}$ exposure of DU145 cells to pancratistatin or Tamoxifen, there was increased expression of LC3 compared to control (Fig. 5B). There was no observable increase in LC3 expression after $24 \mathrm{~h}$

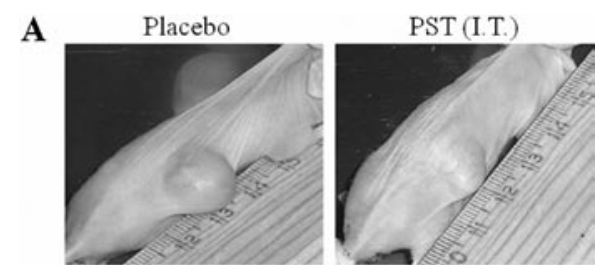

B

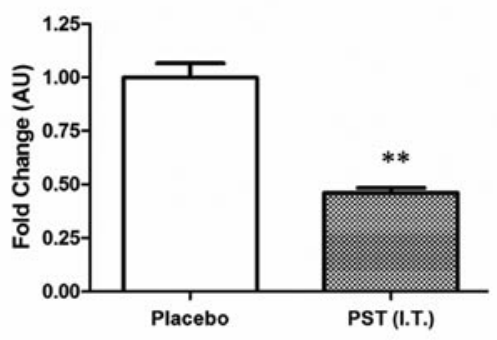

C

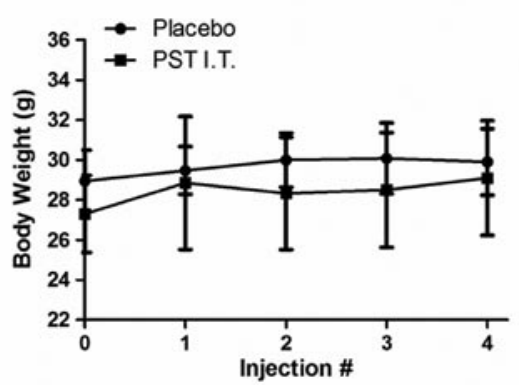

Figure 6. Pancratistatin reduces growth of human prostate tumor xenografts (A) Representative images of DU145 tumor xenografts in control $\left(\mathrm{Me}_{2} \mathrm{SO}\right)$ and $3 \mathrm{mg} / \mathrm{kg}$ pancratistatin (PST)-treated (IT) $\mathrm{Nu} / \mathrm{Nu}$ immune-compromised mice. (B) Fold-difference of tumor volume between control and PST treated mice upon completion of the study. Columns, mean ( $\mathrm{n}=3$ ); bars, $\mathrm{SD} ;{ }^{* *} \mathrm{P}<0.005$, significantly different from control by paired t-test. (C) Average body weights of control $\left(\mathrm{Me}_{2} \mathrm{SO}\right)$ and pancratistatin (PST)-treated $(3 \mathrm{mg} / \mathrm{kg}, \mathrm{IT})$ mice. The body weights of control and PST-treated mice did not vary significantly throughout the study. Data points, mean $(n=3)$; bars, SD.

pancratistatin treatment compared to control. These data indicate that pancratistatin induces autophagy in androgen- 
independent, p53-mutant prostate cancer cells and contributes to the cell death response.

Anti-tumor effect of pancratistatin on prostate tumor xenografts. To assess the efficacy of pancratistatin in vivo, we tested its anti-tumor potential against human prostate tumor xenografts grown in immune-compromised mice. In this proof-of-concept study, pancratistatin $(3 \mathrm{mg} / \mathrm{kg}$ ) or vehicle (5 $\mu \mathrm{l} \mathrm{Me}_{2} \mathrm{SO}$ in PBS) was administered i.t. four times over 3 weeks in animals bearing DU145 xenografts. After the final treatment, the average tumor volume in pancratistatin-treated mice was approximately $50 \%$ smaller than that of vehicletreated mice (Fig. 6A and B). The average body weight of the animals did not vary significantly between treatment groups throughout the study (Fig. 6C). Importantly, there were no observable signs of stress such as redness or swelling at the injection site or change in activity/behaviour of animals receiving pancratistatin compared to control (not shown). This finding suggests that pancratistatin has anti-tumor activity against human prostate cancer in vivo, and is well-tolerated by mice at the dosage tested.

\section{Discussion}

Metastatic prostate cancer is typically androgen-refractory and treatment options are limited for advanced stages of the disease. It is proposed that resistance to chemotherapy, specifically endocrine therapy, is a result of cancer cell protection through evasion of apoptosis and/or induction of autophagy. Avoidance of apoptosis is considered one of the hallmarks of cancer, and stimulation of apoptosis is the primary aim of many anti-cancer drugs (28). In tumor cells, the process of autophagy is thought to promote survival in adverse conditions of the tumor microenvironment, including chemotherapeutic insult. Autophagy is a process of self-digestion used by cells in times of starvation, or in attempt to clear damaged proteins/ organelles from the cell (29). Thus, inhibition of autophagy has become an attractive approach to modulate resistance of tumor cells to chemotherapy agents $(15,19)$.

The interplay between autophagy and apoptosis has garnered significant interest in the past few years, and it has come to light that proteins traditionally viewed as pro-apoptotic or anti-apoptotic are also important regulators of autophagy $(14,15,20)$. The quintessential tumor suppressor p53 may be viewed as a central player in both processes, as it is known to induce apoptosis and inhibit autophagy $(30,31)$. In response to extensive DNA damage or other lethal stressors, pro-apoptotic proteins such as Bax and puma become activated by p53 and result in mitochondrial-mediated apoptosis (31). Functional p53 inhibits autophagy directly, by activation of DRAM (damage-regulated autophagy modulator), or indirectly through suppression of mTOR - the primary regulator of survival autophagy (20).

It is suggested that over half of human cancers have functionally inactive p53 mutations (31). Lack-of-function mutations of p53 allow tumor cells to escape apoptosis, use autophagy to protect against stressors, and survive on enhanced glycolysis. Mitochondria of cancer cells are purportedly more vulnerable to attack than non-cancerous cell mitochondria, due to their aberrant metabolic reprogramming (8). Cancer cells, unlike normal cells, primarily use glycolysis for production of ATP, and largely bypass oxidative phosphorylation (Warburg effect). Another abnormality of cancer cells is that their rapid rate of proliferation may result in improper lipid remodelling of mitochondrial membranes (as well as other organelles), making cancer cell mitochondria more susceptible to disruption (32). In this report, our findings suggest that pancratistatin directly targets the mitochondria and leads to p53-independent cell death.

Our results indicate that pancratistatin induces cell death with features characteristic to apoptosis, decreases migratory capacity and elicits an autophagy response in metastatic prostate cancer cells. We suspect that pancratistatin induces autophagic cell death in prostate cancer cells, rather than protective autophagy, due to the extensive apoptosis observed following treatment. Importantly, as proof-of-concept, we report that intra-tumor administration of pancratistatin caused a significant reduction in the growth of DU145 xenograft tumors in immune-compromised mice. The concentration of pancratistatin used in vivo $(3 \mathrm{mg} / \mathrm{kg})$ is well under the previously determined maximum tolerated dose (24). There was no morbidity due to treatment, nor was there drastic variation in activity level or significant weight loss/gain between control and treated animals, indicating low toxicity.

Herein, we report for the first time that pancratistatin induced apoptosis and autophagic cell death in metastatic prostate cancer cells. In addition, pancratistatin was shown to have anti-tumor activity on human prostate tumors in vivo. Pancratistatin treatment caused increased ROS production and loss of mitochondrial membrane potential, and the novel finding that pancratistatin decreased the migratory capacity of metastatic prostate cancer cells. Taken together, these results demonstrate that pancratistatin is a potent and selective natural anti-cancer compound that may be an effective treatment option for metastatic prostate cancer, independent of p53-status and hormone-sensitivity.

\section{Acknowledgements}

This study was supported by the Lotte \& John Hecht Memorial Foundation of Vancouver, B.C., Canada (S.P. and J.M.), Knights of Columbus Council 9671 (SP), a Partnership Development Seed Grant from the Shastri Indo-Canadian Institute of Calgary (S.P.), and by a CIHR Banting \& Best Doctoral Fellowship (C.G.). The authors declare no conflicts of interest.

\section{References}

1. Kornienko A and Evidente A: Chemistry, biology, and medicinal potential of narciclasine and its congeners. Chem Rev 108: 1982-2014, 2008

2. Griffin C, Karnik A, McNulty J and Pandey S: Pancratistatin selectively targets cancer cell mitochondria and reduces growth of human colon tumor xenografts. Mol Cancer Ther 10: 57-68, 2011.

3. Kekre N, Griffin C, McNulty J and Pandey S: Pancratistatin causes early activation of caspase- 3 and the flipping of phosphatidyl serine followed by rapid apoptosis specifically in human lymphoma cells. Cancer Chemother Pharmacol 56: 29-38, 2005.

4. Chatterjee SJ, McNulty J and Pandey S: Sensitization of human melanoma cells by tamoxifen to apoptosis induction by pancratistatin, a nongenotoxic natural compound. Melanoma Res (In press). 
5. Siedlakowski P, McLachlan-Burgess A, Griffin C, Tirumalai SS McNulty J and Pandey S: Synergy of pancratistatin and tamoxifen on breast cancer cells in inducing apoptosis by targeting mitochondria. Cancer Biol Ther 7: 376-384, 2007.

6. Ralph SJ, Rodríguez-Enríquez S, Neuzil J and Moreno-Sánchez R: Bioenergetic pathways in tumor mitochondria as targets for cancer therapy and the importance of the ROS-induced apoptotic trigger. Mol Aspects Med 31: 29-59, 2010.

7. Valko M, Leibfritz D, Moncol J, Cronin MT, Mazur M and Telser J: Free radicals and antioxidants in normal physiological functions and human disease. Int J Biochem Cell Biol 39: 44-84, 2007.

8. Fulda S, Galluzzi L and Kroemer G: Targeting mitochondria for cancer therapy. Nat Rev Drug Discov 9: 447-464, 2010.

9. Liu EH, Qi LW, Wu Q, Peng YB and Li P: Anticancer agents derived from natural products. Mini Rev Med Chem 9: 1547-1555, 2009.

10. Neuzil J, Wang XF, Dong LF, Low P and Ralph SJ: Molecular mechanism of 'mitocan'-induced apoptosis in cancer cells epitomizes the multiple roles of reactive oxygen species and Bcl-2 family proteins. FEBS Lett 580: 5125-5129, 2006.

11. Dong LF, Freeman R, Liu J, Zobalova R, Marin-Hernandez A Stantic M, Rohlena J, Valis K, Rodriguez-Enriquez S, Butcher B, Goodwin J, Brunk UT, Witting PK, Moreno-Sanchez R, Scheffler IE, Ralph SJ and Neuzil J: Suppression of tumor growth in vivo by the mitocan alpha-tocopheryl succinate requires respiratory complex II. Clin Cancer Res 15: 1593-1600, 2009.

12. Xiao D, Powolny AA, Moura MB, Kelley EE, Bommareddy A, Kim SH, Hahm ER, Normolle D, van Houten B and Singh SV: Phenethyl isothiocyanate inhibits oxidative phosphorylation to trigger reactive oxygen species-mediated death of human prostate cancer cells. J Biol Chem 285: 26558-26569, 2010.

13. DiPaola RS, Dvorzhinski D, Thalasila A, Garikapaty V, Doram D, May M, Bray K, Mathew R, Beaudoin B, Karp C, Stein M, Foran DJ and White E: Therapeutic starvation and autophagy in prostate cancer: a new paradigm for targeting metabolism in cancer therapy. Prostate 68: 1743-1752, 2008.

14. Fimia GM and Piacentini M: Regulation of autophagy in mammals and its interplay with apoptosis. Cell Mol Life Sci 67: 1581-1588, 2010.

15. Dalby KN, Tekedereli I, Lopez-Berestein G and Ozpolat B Targeting the prodeath and prosurvival functions of autophagy as novel therapeutic strategies in cancer. Autophagy 6: 322-329, 2010.

16. Qadir MA, Kwok B, Dragowska WH, To KH, Le D, Bally MB and Gorski SM: Macroautophagy inhibition sensitizes tamoxifenresistant breast cancer cells and enhances mitochondrial depolarization. Breast Cancer Res Treat 112: 389-403, 2008.

17. Morselli E, Galluzzi L, Kepp O, Vicencio JM, Criollo A, Maiuri MC and Kroemer G: Anti- and pro-tumor functions of autophagy. Biochim Biophys Acta 1793: 1524-1532, 2009.
18. Gibson SB: A matter of balance between life and death: targeting reactive oxygen species (ROS)-induced autophagy for cancer therapy. Autophagy 6: 835-837, 2010.

19. White E and DiPaola RS: The double-edged sword of autophagy modulation in cancer. Clin Cancer Res 15: 5308-5316, 2009.

20. Olovnikova IA, Kravchenkoa JE and Chumakov PM: Homeostatic functions of the p53 tumor suppressor: Regulation of energy metabolism and antioxidant defence. Sem Can Biol 19: 32-41, 2009.

21. Radhakrishnan S, Miranda E, Ekblad M, Holford A, Pizarro MT, Lemoine NR and Halldén G: Efficacy of oncolytic mutants targeting $\mathrm{pRb}$ and $\mathrm{p} 53$ pathways is synergistically enhanced when combined with cytotoxic drugs in prostate cancer cells and tumor xenografts. Hum Gene Ther 21: 1311-1325, 2010.

22. McNulty J, Mao J, Gibe R, Mo R, Wolf S, Pettit GR, Herald DL and Boyd MR: Studies directed towards the refinement of the pancratistatin cytotoxic pharmacophore. Bioorg Med Chem Lett 11: 169-172, 2001

23. Hu H, Lee HJ, Jiang C, Zhang J, Wang L, Zhao Y, Xiang Q, Lee EO, Kim SH and Lü J: Penta-1,2,3,4,6-O-galloyl-beta-Dglucose induces p53 and inhibits STAT3 in prostate cancer cells in vitro and suppresses prostate xenograft tumor growth in vivo. Mol Cancer Ther 7: 2681-2691, 2008.

24. Gabrielsen B, Monath TP, Huggins JW, Kefauver DF, Pettit GR, Groszek G, Hollingshead M, Kirsi JJ, Shannon WM and Schubert EM: Antiviral (RNA) activity of selected Amaryllidaceae isoquinoline constituents and synthesis of related substances. J Nat Prod 55: 1569-1581, 1992.

25. Shah MR, Kriedt CL, Lents NH, Hoyer MK, Jamaluddin N, Klein $\mathrm{C}$ and Baldassare J: Direct intra-tumoral injection of zincacetate halts tumor growth in a xenograft model of prostate cancer. J Exp Clin Cancer Res 28: 84, 2009.

26. Griffin C, Hamm C, McNulty J and Pandey S: Pancratistatin induces apoptosis in clinical leukemia samples with minimal effect on non-cancerous peripheral blood mononuclear cells. Cancer Cell Int 10: 6, 2010.

27. Wang F, Ogasawara MA and Huang P: Small mitochondriatargeting molecules as anti-cancer agents. Mol Asp Med 31: 75-92, 2010.

28. Hanahan D and Weinberg RA: The hallmarks of cancer. Cell 100: 57-70, 2000

29. Levine B: Cell biology: Autophagy and cancer. Nature Q\&A 446: 745-747, 2007.

30. Galluzzi L, Morselli E, Kepp O, Vitale I, Pinti M and Kroemer G: Mitochondrial liaisons of p53. Antioxid Redox Signal (In press).

31. Green DR and Kroemer G: Cytoplasmic functions of the tumour suppressor p53. Nature 458: 1127-1130, 2009.

32. Alirol E and Martinou JC: Mitochondria and cancer: is there a morphological connection? Oncogene 25: 4706-4716, 2006. 